\title{
The Clinicopathological Features and Staging at Presentation of Gastric Cancer: A Single-Center Retrospective Study
}

\author{
Syn Yi Chong ${ }^{1}$ Soo Fan Ang ${ }^{2}$ \\ 1 Perdana University Graduate School of Medicine, Serdang, \\ Selangor, Malaysia \\ ${ }^{2}$ Adventist Oncology Centre, Penang Adventist Hospital, \\ Georgetown, Penang, Malaysia \\ Asian J Oncol:2020;6:120-126
}

\begin{abstract}
Address for correspondence Soo Fan Ang, MBBS, MRCP, FAMS, Penang Adventist Hospital, 465, Jalan Burma, Georgetown, 10350 Penang, Malaysia (e-mail: chongsynyi@gmail.com).
\end{abstract}

\begin{abstract}
Introduction Gastric cancer (GC) is the third leading cause of cancer death, with most patients diagnosed at a later stage, with distant metastasis at the time of presentation, contributing to poor prognosis. GC has been associated with nonspecific clinical presentations, which cause a time delay for patients to seek for medical advice. This study aims to identify the clinicopathological features of GC patients and correlate time delay of the diagnosis to the staging of the disease.

Materials and Methods This is a single-center retrospective study of GC patients diagnosed from January 2012 to December 2018. All relevant data of GC patient diagnosed during this time period were extracted from the patients' case notes.

Results A total of 69 GC patients were included in this study, with male preponderance and mean age of 62 years old. The top three symptoms presented are dyspepsia or ingestion (47.8\%), weight loss (43.5\%), and nausea or vomiting (33.3\%). The mean time delay was 3.7 months. Patients presented with weight loss have a significantly longer average time delay of 4.88 months. Most tumor lesion was found at the distal stomach (43.5\%), while 74.5\% tested negative for Helicobacter pylori. Most patients were diagnosed at Stage IV (52.6\%) and Stage III (36.8\%) of the disease, with poorly differentiated (67.7\%) histological features which have poor prognosis.

\section{Keywords}

- gastric cancer

- presenting symptoms

- stage at presentation

Discussion and Conclusion No evidence of specific symptom or combination of symptoms predicts higher risk of GC. Regardless of the number of symptoms presented or the time delay, most GC patients were diagnosed at later stage of the disease. The study shows the importance of GC screening in Malaysia to ensure early detection, even before a symptom presented.
\end{abstract}

\section{Introduction}

Gastric cancer (GC) accounts for $5.7 \%$ of total cancer incidence worldwide, which is approximately 1.0 million new cancer cases based on GLOBOCAN estimates in 2018. It is the third leading cause of cancer death (8.2\%) after lung cancer and colorectal cancer, equating to 1 in every 12 deaths globally. ${ }^{1}$ This is perhaps due to the fact that GC is often detected late, with distant metastasis at the time of diagnosis, contributing to poor prognosis. ${ }^{2}$ Maconi et $\mathrm{al}^{3}$ suggested that GC is often detected at the later stage of metastasis due to nonspecific clinical presentation such as bloating and epigastric pain, while alarming symptoms such as dysphagia, anorexia, weight loss, gastrointestinal (GI) bleeding, vomiting, and anemia only occurs in minority of the patients. The study shows that the presence of, at least, one of the alarming symptoms might reduce the 5 -year survival rate by an average of $26 \%{ }^{3}$ Hence, early detection in GC, prior to the emergence of such
DOI https://doi.org/

10.1055/s-0040-1714307

ISSN 2454-6798.
License terms

() (1) $\ominus \circledast$ 
alarming symptoms, may improve the prognosis of the disease. However, time delay in GC diagnosis remains a major issue in Malaysia. A study conducted among 112 gastric and esophageal cancer patients in Malaysia reported that the mean duration from the first appearance of cancer symptoms to endoscope procedure was 32.4 weeks, which is approximately 5 months. ${ }^{4}$ Although there is a study which suggested that diagnostic delay of 6 months for cases of uncomplicated dyspepsia may not have an effect on patient's survival, ${ }^{3}$ but not enough evidence had been collected to show how other clinical presentations correlates to staging of the disease. It has been well-established that clinicopathological features of the tumors are important in evaluating the disease prognosis, likewise in deciding treatment regime. ${ }^{5}$ This study therefore aims to identify common clinical presentations of GC, features of the tumor, and cancer staging at the time of diagnosis in Penang Adventist Hospital. Meanwhile, time delay was also evaluated by identifying the duration from which the symptoms presented was first recognized by the patient to the time of diagnosis.

\section{Materials and Methods}

A retrospective review of patients diagnosed with GC at Penang Adventist Hospital, Malaysia, for the period January 2012 to December 2018 was performed. Relevant data has been extracted from patients' case notes, including laboratory reports, oesophagogastroduodenoscopy (OGDS), and histological and imaging studies.

\section{Definition and Stratification}

Data of patient's presenting symptoms are collected based on complaints recorded in the medical notes during the first visit. Imaging studies, such as OGDS and CT or PET-CT report, are based on the first report available during or after the first patient's visit. Tumor sites are categorized into three parts, gastroesophageal junction, proximal and distal stomach, where proximal stomach includes the cardia, fundus and body, while distal stomach comprises the antrum and pylorus of the stomach.

Date of initial diagnosis of gastric cancer is based on the date of which the histological report was released. Information regarding the features of the tumor were extracted from the histological report in which the date of initial diagnosis was taken. Histological subtype of the gastric cancer was classified according to Lauren's criteria as intestinal, diffused and indeterminate type. Tumor histological reports in which Lauren's criteria were not mentioned were classified under indeterminate/unknown subtype.

Preoperative cancer markers, carbohydrate antigen (CA 19-9), and carcinoembryonic antigen (CEA) values were recorded, and each was classified into three groups. CA 19-9 value $<35 \mathrm{U} / \mathrm{mL}$ is classified as CA 19-9 Group 1 , which is also recognized as negative. Patients with CA 19-9 between 35 and $100 \mathrm{U} / \mathrm{mL}$ were classified in Group 2, while those $>100$ $\mathrm{U} / \mathrm{mL}$ are classified in Group 3. Patients were recognized as negative for CEA marker when classified in CEA Group 1, with CEA value $<5 \mathrm{ng} / \mathrm{mL}$. Patients with CEA value ranges between 5 and $30 \mathrm{ng} / \mathrm{mL}$ and $>30 \mathrm{ng} / \mathrm{mL}$ were classified in Group 2 and 3, respectively.

\section{Statistical Analysis}

The statistical analyses were done using SPSS software for Window version 23.0. A descriptive analysis for each parameter was performed, which included the mean, standard deviation (SD), frequencies and percentages for all demographic characteristics, presenting symptoms and staging of cancer at presentation. Missing data were excluded when statistical analyses were applied. The Mann-Whitney $\mathrm{U}$ test will be used to assess the difference of the means between two independent groups. Comparisons were done on qualitative data using Pearson's Chi-squared test, where $p<0.05$ was recognized as statistically significant.

\section{Results}

The study involved 69 patients $(n=69)$ diagnosed with GC from year 2012 to 2018 at Penang Adventist Hospital. The subjects included in the data analysis had a mean age of 62 years $(\mathrm{SE}=1.679$, median age $=62$; range $=28-87)$ at the point of diagnosis. There were more male than female patients, with 42 males (60.9\%) and 27 females (39.1\%). Most patients were Chinese (60.9\%), followed by Indonesian (36.2\%), while Indians and other races constituted a minimal portion of this cohort, which is only $1.4 \%$ in each group (-Table 1 ). Mean body mass index (BMI) of the subjects is 23.15 ( $\mathrm{SE}=0.588$ ). Patients with blood group $\mathrm{O}$ comprised the majority of the patients, 42.6\%, followed by blood group A (29.8\%), B (17.0\%), and blood group $A B$ being the least (10.5\%).

Smokers and ex-smokers are categorized as one group. There were more non-smokers (65.2\%) than smokers (34.8\%) among the study cohort. Meanwhile, patients who reported to be alcohol drinkers only constituted $14.5 \%$, while most (84.1\%) did not drink alcohol. Patients with GC who were also afflicted with diabetes mellitus, hypertension and hypercholesterolemia were $14.5,30.4$, and $14.5 \%$, respectively, of the total sample size (-Table 1).

\section{Presenting Symptoms and Time delay for Diagnosis}

Most patients presented to the clinic with complaint of dyspepsia or ingestion (47.8\%), followed by weight loss and nausea or vomiting accounting for 43.5 and $33.3 \%$, respectively. Other symptoms which are commonly reported included epigastric pain (24.6\%), dysphagia (24.6\%), anemia (15.9\%), abdominal pain (14.5\%), and bloating (13.0\%). Symptoms which are only reported by five or less patients among the total subject group were categorized under "others," including tiredness, altered bowel habit, altered taste, loss of appetite, chest pain/discomfort, melena, back pain, hematemesis, neck pain, flatulence, and syncope. As much as $31.9 \%$ of the patients exhibited at least one of the symptoms included in the "others" category (-Table 2).

Most patients complained of one to three symptoms during presentation. As much as $23.2 \%$ of the patients reported one symptom, $29 \%$ reported two symptoms, while $23.2 \%$ reported three symptoms. Only a small group of patient 
Table 1 Demographic data distributed according to gender, ethnicity, blood type, smoking status, alcohol intake, and associated medical conditions (i.e., diabetes mellitus, hypertension and hypercholesterolemia)

\begin{tabular}{|c|c|c|}
\hline & Frequency & Percentage (\%) \\
\hline \multicolumn{3}{|l|}{ Gender $(n=69)$} \\
\hline Male & 42 & 60.9 \\
\hline Female & 27 & 39.1 \\
\hline \multicolumn{3}{|l|}{ Ethnicity $(n=69)$} \\
\hline Chinese & 42 & 60.9 \\
\hline Indonesian & 25 & 36.2 \\
\hline Indian & 1 & 1.4 \\
\hline Others & 1 & 1.4 \\
\hline \multicolumn{3}{|c|}{ Blood types $(n=47 ;$ missing $=22)$} \\
\hline A & 14 & 29.8 \\
\hline $\mathrm{B}$ & 8 & 17.0 \\
\hline $\mathrm{O}$ & 20 & 42.6 \\
\hline No & 5 & 10.6 \\
\hline \multicolumn{3}{|l|}{ Smoking $(n=69)$} \\
\hline $\begin{array}{l}\text { Smoker/ } \\
\text { Ex-Smoker }\end{array}$ & 24 & 34.8 \\
\hline Non-Smoker & 45 & 65.2 \\
\hline \multicolumn{3}{|l|}{ Alcohol $(n=69)$} \\
\hline Drink alcohol & 11 & 15.9 \\
\hline $\begin{array}{l}\text { Do not drink } \\
\text { alcohol }\end{array}$ & 58 & 84.1 \\
\hline \multicolumn{3}{|c|}{ Diabetes Mellitus ( $n=69$ ) } \\
\hline Yes & 10 & 14.5 \\
\hline No & 59 & 85.5 \\
\hline \multicolumn{3}{|c|}{ Hypertension $(n=69)$} \\
\hline Yes & 21 & 30.4 \\
\hline No & 48 & 69.6 \\
\hline \multicolumn{3}{|c|}{ Hypercholesterolemia $(n=69)$} \\
\hline Yes & 10 & 14.5 \\
\hline No & 59 & 85.5 \\
\hline
\end{tabular}

presented with more than three complaints, $14.5 \%$ with four symptoms, and $7.2 \%$ reported to have five symptoms. The maximum number of symptoms reported by an individual patient was six, which accounted for two out of 69 patients (2.9\%). Data collected shows that the time delay from when the patient first noticed the symptom mentioned to the point where initial diagnosis of gastric cancer was confirmed ranges from 0.1 month to 17.7 months (more than 1 year), with a mean of 3.7 months ( $\mathrm{SE}=0.4187$, median 2.533 ).

Most patients (55.1\%) were diagnosed within 3 months, $23.2 \%$ has a time delay between 3 to 6 months, while $21.7 \%$ patients were diagnosed 6 months after they first noticed the symptom. There were no significant differences of time delay for GC diagnosis between patients who presented with a symptom and those who did not, with the exception of the patient group who presented with weight loss. - Table 2 shows that the patient group which showed weight loss had a significantly longer mean time delay compared with the group of patients who did not experience weight loss ( $p \leq 0.05$ ). Interestingly, loss of weight is also the presenting symptom which has the longest time delay, with a mean time delay of 4.88 months in the positive group, and an average difference of 0.88 month time delay compared with the other symptoms.

\section{Clinical Findings and Tumor Features}

OGDS reports ( $n=61$ ) shows that tumor is observed during the OGDS procedure in $68.9 \%$ of the cases. As much as $50.8 \%$ have ulcer present, while gastritis and esophageal reflux were present in 27.9 and $21.3 \%$ of the cases, respectively. Most tumor or lesion are found at the distal part of the stomach $(43.5 \%)$ followed by proximal stomach (37.1\%) and gastroesophageal junction (19.4\%) with $n=62$. Crosstab analysis shows that $64.7 \%$ of those with dysphagia had tumor at the gastroesophageal junction, with $p<0.05$ indicating association of dysphagia with tumor at the gastroesophageal junction. However, this has an expected count of less than five, which may indicate inaccuracy of this statistics. Chi-squared test shows no significant associations between the site of tumor and other presenting symptoms. Among 61 subjects whose OGDS reports were available, only $25.5 \%$ of the biopsies done tested positive for Helicobacter pylori (- Table 3).

Histological studies show that all of the cases recorded showed adenocarcinoma. As much as $67.7 \%$ are poorly differentiated, $27.4 \%$ are categorized as intermediate, while only $4.8 \%$ are well-differentiated. In $41.8 \%$ of the cases, Signet ring cell was present. The type of gastric tumor was classified based on Lauren's criteria, where $26.5 \%$ were part of the intestinal group, 35.3\% were diffused, and the majority (38.2\%) were indeterminate/unknown (-Table 4). Tumor marker CA 19.9 and CEA markers were lower in most GC patients among the study subjects at the time of diagnosis. CA $19.9<35 \mathrm{U} /$ $\mathrm{mL}$, referring to the negative group, accounts for $60 \%$ of the cases $(n=50)$. Only one of the GC cases has $35-100 \mathrm{U} / \mathrm{mL}(2 \%)$, while $38 \%$ has elevated CA 19.9 level. CEA marker was available in 54 of the reports $(n=54)$, with $72.2 \%$ of the patients having a very low value, $<5 \mathrm{ng} / \mathrm{mL}$. As much as $18.5 \%$ had CEA marker reading ranging from 5 to $30 \mathrm{ng} / \mathrm{mL}$ and only $9.3 \%$ had > $30 \mathrm{ng} / \mathrm{mL}$ CEA markers at baseline (- Table 5 ).

\section{Staging at Presentation}

Most patients with GC were diagnosed to be at the later stage at the time of presentation. Among 57 patients whose stage of cancer was appropriately assessed or documented, 30 were diagnosed with Stage IV (52.6\%), 21 out of 57 (36.8\%) were in Stage III, $8.8 \%$ diagnosed with Stage II, while only one patient out of $57(1.8 \%)$ was in Stage I at the time of presentation. Crosstabs analysis on the relationship between each presenting symptom and stage of the disease at presentation shows no evidence of an association using standard Chi-squared test of independence. Duration of time delay in diagnosis also shows insignificant difference between stages of GC. There is no significant difference of CA 19.9 and CEA cancer marker 
Table 2 Presenting symptoms and the mean time delay (i.e., patient first reported of the presenting symptom(s) to the time of diagnosis), with significance of mean difference assessed using Mann-Whitney $U$-test, where $p<0.05$ is recognized as statistically significant

\begin{tabular}{|c|c|c|c|c|c|c|}
\hline \multirow{2}{*}{\multicolumn{2}{|c|}{$N$}} & \multirow[t]{2}{*}{ Percentage (\%) } & \multirow[t]{2}{*}{ Rank } & \multicolumn{2}{|c|}{ Time delay } & \multirow[t]{2}{*}{ Significance } \\
\hline & & & & Mean & SD & \\
\hline \multicolumn{7}{|c|}{ Dyspepsia/ingestion ( $n=69$ ) } \\
\hline Yes & 33 & 47.8 & 1 & 4.17 & 3.68 & \multirow[t]{2}{*}{0.146} \\
\hline No & 36 & 52.2 & & 3.33 & 3.29 & \\
\hline \multicolumn{7}{|c|}{ Nausea/vomiting $(n=69)$} \\
\hline Yes & 23 & 33.3 & 3 & 3.92 & 3.92 & \multirow[t]{2}{*}{0.638} \\
\hline No & 46 & 66.7 & & 3.64 & 3.28 & \\
\hline \multicolumn{7}{|c|}{ Epigastric pain $(n=69)$} \\
\hline Yes & 17 & 24.6 & 4 & 4.72 & 4.46 & \multirow[t]{2}{*}{0.162} \\
\hline No & 52 & 75.4 & & 3.41 & 3.07 & \\
\hline \multicolumn{7}{|c|}{ Loss of weight $(n=69)$} \\
\hline Yes & 30 & 43.5 & 2 & 4.88 & 4.01 & \multirow[t]{2}{*}{0.006} \\
\hline No & 39 & 56.5 & & 2.84 & 2.75 & \\
\hline \multicolumn{7}{|c|}{ Anemia $(n=69)$} \\
\hline Yes & 11 & 15.9 & 5 & 2.57 & 2.31 & \multirow[t]{2}{*}{0.238} \\
\hline No & 58 & 84.1 & & 3.95 & 3.63 & \\
\hline \multicolumn{7}{|c|}{ Abdominal pain $(n=69)$} \\
\hline Yes & 10 & 14.5 & 6 & 4.13 & 3.32 & \multirow[t]{2}{*}{0.357} \\
\hline No & 59 & 85.5 & & 3.66 & 3.53 & \\
\hline \multicolumn{7}{|c|}{ Dysphagia $(n=69)$} \\
\hline Yes & 17 & 24.6 & 4 & 3.37 & 3.13 & \multirow[t]{2}{*}{0.770} \\
\hline No & 52 & 75.4 & & 3.85 & 3.60 & \\
\hline \multicolumn{7}{|c|}{ Bloating $(n=69)$} \\
\hline Yes & 9 & 13.0 & 7 & 4.50 & 3.45 & \multirow[t]{2}{*}{0.310} \\
\hline No & 60 & 87.0 & & 3.61 & 3.50 & \\
\hline \multicolumn{7}{|c|}{ Others $(n=69)$} \\
\hline Yes & 22 & 31.9 & - & 4.59 & 3.65 & \multirow[t]{2}{*}{0.172} \\
\hline No & 47 & 68.1 & & 3.33 & 3.35 & \\
\hline
\end{tabular}

levels between the patients in Stage I to IV of GC at the time of diagnosis.

\section{Discussion}

The results of this study show a male preponderance (60.9\%) in GC patients, with mean age of 62 years. This supports global epidemiological studies, where GC was diagnosed in males 2.2 times more compare with females, which may due to protective effect of estrogen against GC. ${ }^{6}$ This idea was further enhanced by the presence of estrogen receptor- $\beta$ in GC tumor that may protect against invasiveness in GC. ${ }^{7}$ Most patients were Chinese and Indonesian, who are the primary service users at the Penang Adventist Hospital. There were a larger proportion of patients who had blood group $\mathrm{O}(42.6 \%)$ compares with blood group A
(29.8\%), This contradicts with most studies which suggest that blood group A will have higher risk of GC than blood group 0 . A study suggested that although GC is more commonly associated with patients with blood group A, GC in blood group $\mathrm{O}$ is associated with increased risk of peptic ulcer disease, which could eventually increase the risk of GC. ${ }^{8}$ Therefore, this finding suggests that the development of GC among most patient in this study cohort may be associated with peptic ulcer disease or other risk factors.

Furthermore, there were only small number of patients (25.5\%) who tested positive for $H$. pylori infection in this study, which was known to be one of the main risk factors for GC and peptic ulcer disease. ${ }^{6}$ These data suggested other etiologies that may have contributed to the development of GC among the Penang population. Although both smoking and alcohol drinking are known risk factors for $\mathrm{GC},{ }^{6}$ the results found in this study shows unexpected demographics, with a 
Table 3 Oesophagogastroduodenoscopy findings at baseline and $H$. pylori biopsy test

\begin{tabular}{|c|c|c|}
\hline & Frequency & Percentage (\%) \\
\hline \multicolumn{3}{|c|}{ Site $(n=62 ;$ missing $=7)$} \\
\hline $\begin{array}{l}\text { Gastroesophageal } \\
\text { junction }\end{array}$ & 12 & 19.4 \\
\hline Proximal stomach & 23 & 37.1 \\
\hline Distal stomach & 27 & 43.5 \\
\hline \multicolumn{3}{|c|}{ Tumor $/$ mass $(n=61 ;$ missing $=8$ ) } \\
\hline Present & 42 & 68.9 \\
\hline Absent & 19 & 31.1 \\
\hline \multicolumn{3}{|c|}{ Ulcer $(n=61 ;$ missing $=8$ ) } \\
\hline Present & 31 & 50.8 \\
\hline Absent & 30 & 49.2 \\
\hline \multicolumn{3}{|c|}{ Gastritis ( $n=61 ;$ missing $=8$ ) } \\
\hline Present & 17 & 27.9 \\
\hline Absent & 44 & 72.1 \\
\hline \multicolumn{3}{|c|}{ Esophageal reflux ( $n=61 ;$ missing $=8$ ) } \\
\hline Present & 13 & 21.3 \\
\hline Absent & 48 & 78.7 \\
\hline \multicolumn{3}{|c|}{ Helicobacter pylori $(n=61 ;$ missing $=8)$} \\
\hline Positive & 13 & 25.5 \\
\hline Negative & 38 & 74.5 \\
\hline
\end{tabular}

Table 4 Histological features of GC tumor

\begin{tabular}{|c|c|c|}
\hline & Frequency & Percentage (\%) \\
\hline \multicolumn{3}{|c|}{ Lauren's classification $(n=68 ;$ missing $=1$ ) } \\
\hline Intestinal & 18 & 26.5 \\
\hline Diffused & 24 & 35.3 \\
\hline $\begin{array}{l}\text { Indeterminated/ } \\
\text { unknown }\end{array}$ & 26 & 38.2 \\
\hline \multicolumn{3}{|c|}{ Signet ring cell $(n=68 ;$ missing $=1)$} \\
\hline Present & 28 & 41.8 \\
\hline Absent & 39 & 58.2 \\
\hline \multicolumn{3}{|c|}{ Grading ( $n=62 ;$ missing $=7$ ) } \\
\hline Well-differentiated & 3 & 4.8 \\
\hline Intermediate & 17 & 27.4 \\
\hline Poorly differentiated & 42 & 67.7 \\
\hline
\end{tabular}

Abbreviation: GC, gastric cancer.

higher proportion of nonsmokers (65.2\%) and nonalcoholics (84.1\%). This may be due to self-report bias among the study cohort, where subjects would tend to deny smoking and alcohol consumption when presented in the clinic, or referred themselves as nonsmokers or nonalcoholics due to the recent halt of the consumption of these substances when they noticed their symptoms. Otherwise, this could be another evidence that suggests other etiologies which contributed to the development of GC among the study cohort, which require further studies in the future. Yusefi et $\mathrm{al}^{9}$ pointed out
Table 5 Tumor marker CA 19.9 and CEA studies, with TNM staging at presentation

\begin{tabular}{|c|c|c|}
\hline & Frequency & Percentage (\%) \\
\hline \multicolumn{3}{|c|}{ CA 19.9 marker $(n=50 ;$ missing $=19)$} \\
\hline$<35 \mathrm{U} / \mathrm{mL}$ & 30 & 60.0 \\
\hline $35-100 \mathrm{U} / \mathrm{mL}$ & 1 & 2.0 \\
\hline$>100 \mathrm{U} / \mathrm{mL}$ & 19 & 38.0 \\
\hline \multicolumn{3}{|c|}{ CEA marker $(n=54 ;$ missing $=15)$} \\
\hline$<5 \mathrm{ng} / \mathrm{mL}$ & 39 & 72.2 \\
\hline $5-30 \mathrm{ng} / \mathrm{mL}$ & 10 & 18.5 \\
\hline$>30 \mathrm{ng} / \mathrm{mL}$ & 5 & 9.3 \\
\hline \multicolumn{3}{|c|}{ TNM staging ( $n=57 ;$ missing $=12$ ) } \\
\hline Stage I & 1 & 1.8 \\
\hline Stage II & 5 & 8.8 \\
\hline Stage III & 21 & 36.8 \\
\hline Stage IV & 30 & 52.6 \\
\hline
\end{tabular}

Abbreviation: TNM, tumor, node, metastasis

that dietary habit is one of the most important risk factors in the incidence of GC in comparison to the 52 risk factors that were reviewed. Recent local studies have shown high-salt intake, ${ }^{10,11}$ and lack of vegetables and fruits ${ }^{12}$ among the general population in Indonesia and Malaysia could be the main contributing factor of GC development in this study cohort. However, since this was not the main focus of the research, and most GC studies conducted in Malaysia often excluded Penang due to its unique population, ${ }^{2}$ further studies involving a larger sample size, focusing on understanding GC etiology among the Penang population, is needed to support this finding.

The top three complaints presented among the study cohort were dyspepsia/ingestion (47.8\%), weight loss (43.5\%), and nausea/vomiting (33.3\%), with mean time delay of 3.7 months. All the symptoms presented are nonspecific, making early detection of GC more challenging. According to Tata et $\mathrm{al}_{1}{ }^{4}$ the common reasons behind the delay of detection was due to the use of self-medication, empirical treatment for dyspepsia using antacid and $\mathrm{H} 2$ antagonist, as well as delayed endoscopy procedures in public health facilities. While endoscopic procedure delay may not be applicable in private healthcare settings in Malaysia, the tendency of the general population to self-medicate and opt for empirical treatment remain relevant, ${ }^{4}$ even among patients who are receiving conventional treatment. ${ }^{13}$

Moreover, most patients present with only one to three symptoms, suggesting the importance of implementation of GC screening; also, general practitioners should have a greater level of suspicion among high-risk patients to diagnose GC. Primary care should take note of patient's symptoms and suspect GC in high-risk patient group, even though patient does not exhibit alarming symptoms. This is evident in countries such as Japan and Korea, where a decrease of incidence and mortality of GC was observed through the implementation of GC screening. ${ }^{14,15}$ Howbeit, the cost-effectiveness of 
implementing such screening in other countries with relatively lower incidence rate remains debatable ${ }^{16}$ and the subsequent issue of overdiagnosis through screening program should be carefully addressed. ${ }^{17}$ Although there is no significant difference between the stages of cancer at presentation among patient groups that were diagnosed within the time delay of 3 months, between 3-6 months and 6 months, our study has shown that further delay of approximately one month (0.88 month) will lead to presentation of weight loss, which may be an indication of disease progression. Weight loss was known to be associated with poor prognosis, where a study has shown the significance of preoperative weight loss as an independent prognostic factor for GC, especially when weight loss is above $10 \%{ }^{18}$

In this study, most GC was found at the distal stomach (43.5\%) and patients were mostly diagnosed at the later stage with poorly differentiated (67.7\%) histological structure of the tumor ( $\mathbf{- T a b l e s} \mathbf{3}$ and $\mathbf{5}$ ). A study ${ }^{19}$ conducted in Malaysia showed that the Chinese population are more likely to have gastric adenocarcinoma located at the noncardia or distal region (73.7\%), while all Chinese possessed diffuse subtype. This explains the common tumor features seen in this study, since the study cohort is largely made up of those with Chinese ethnicity and Indonesians, who may also be of Chinese origin. Regardless of the time delay and the number or types of presenting symptoms the patients reported, most patients were diagnosed at an advanced stage, where $52.6 \%$ were in Stage IV and 36.8\% were in Stage III upon diagnosis. As much as $67.7 \%$ had poorly differentiated tumor, which has a poor prognosis. Meanwhile, most GC patients in this study cohort were part of the negative group for CA19.9 and CEA tumor markers, where $60 \%$ had $<35 \mathrm{U} / \mathrm{mL}$ CA19.9 reading and $72.2 \%$ has CEA tumor marker $<5 \mathrm{ng} / \mathrm{mL}$. This could mean that CA 19.9 and CEA tumor marker studies are not suitable to be used as screening tool in GC; however other studies have shown prognostic values, ${ }^{20}$ especially CEA marker in early GC, ${ }^{21}$ although the usefulness of both tumor markers remain debatable. ${ }^{22}$

\section{Limitation of the Study}

Since the study adapted a retrospective analysis design, statistical biases due to missing data, which were not collected or documented at the point of time, were inevitable. Selection bias emerged mostly because the study was conducted in a single center, in which the study cohort comprised mainly Chinese and Indonesians, due to the uniqueness of Penang as a medical tourism spot. As discussed above, further studies are required to conclude the significance of other etiologies in GC development in Penang, correlation of clinicopathological features of GC, and stage of the disease at presentation.

\section{Conclusion}

Dyspepsia, loss of weight, and nausea/vomiting were the top three symptoms presented among the study cohort. There is no evidence of specific symptom or combination of symptoms which would indicate higher risk of GC. Regardless of the number of symptoms presented by the patients and the time delay for diagnosis, most GC patients are diagnosed at the later stage of the disease, which has poor prognosis. This study therefore demonstrates the importance of development of GC screening criteria for high-risk patients based on risk factors and demographics, even prior to any symptoms presented. This is because there have been no significant presenting symptoms that could indicate an early stage of GC, neither is there a cutoff time which could be used as guideline for the general public on when to visit a clinic when a presenting symptom persisted for a period of time (i.e., time delay). Healthcare professionals may lower the threshold to perform OGDS, especially on elderly patients who have gastrointestinal-related symptoms over a span of time to ensure early detection. Further studies are required to provide guidelines for primary care practitioners on referring patients to OGDS. More importantly, there is a need to increase awareness of gastric cancer to decrease the time delay for patient to visit the clinic or being referred to a gastroenterologist.

\section{Note}

The study was approved by the Penang Adventist Hospital Ethics Research Committee (Action No.: RC2019-002) and the Perdana University Institutional Review Board (Ref No.: PU-IRB/MKV/0214/510).

\section{Conflict of Interest}

None declared.

\section{Acknowledgments}

The authors would like to appreciate Dr. Prarthana Gopalakrishna Kalerammana and Dr. Deepthi Shridhar for their guidance throughout the undertaking of this study. A special thanks to Lim Luen Hui from Adventist Clinical Research Centre, who worked collaboratively in ensuring smooth operation and storage of research data throughout the study period, and Tanat Chanrachakul, from Newcastle University Malaysia, who helped in data collection. The authors also appreciate the collective efforts of the staff in the oncology and medical record departments at the Penang Adventist Hospital for making the compilation of the data in this research feasible, and would like to thank the administrative board of Penang Adventist Hospital for approving the study.

\section{References}

1 Bray F, Ferlay J, Soerjomataram I, Siegel RL, Torre LA, Jemal A. Global cancer statistics 2018: GLOBOCAN estimates of incidence and mortality worldwide for 36 cancers in 185 countries. CA Cancer J Clin 2018;68(6):394-424

2 Pourhoseingholi MA, Vahedi M, Baghestani AR. Burden of gastrointestinal cancer in Asia; an overview. Gastroenterol Hepatol Bed Bench 2015;8(1):19-27

3 Maconi G, Manes G, Porro G-B. Role of symptoms in diagnosis and outcome of gastric cancer. World J Gastroenterol 2008;14(8):1149-1155 
4 Tata MD, Dharmendran R, Ramesh G, Kandasami P. Delay in diagnosis of upper gastrointestinal cancer: whose fault is it? Med J Malaysia 2013;68(3):275-277

5 Han J, Tu J, Tang C, Ma X, Huang C. Clinicopathological characteristics and prognosis of cT1N0M1 gastric cancer: a population-based study. Dis Markers 2019;2019:5902091

6 Rawla P, Barsouk A. Epidemiology of gastric cancer: global trends, risk factors and prevention. Prz Gastroenterol 2019;14(1):26-38

7 Ryu WS, Kim JH, Jang Y-J, et al. Expression of estrogen receptors in gastric cancer and their clinical significance. J Surg Oncol 2012;106(4):456-461

8 Edgren G, Hjalgrim H, Rostgaard K, et al. Risk of gastric cancer and peptic ulcers in relation to ABO blood type: a cohort study. Am J Epidemiol 2010;172(11):1280-1285

9 Yusefi AR, Bagheri Lankarani K, Bastani P, Radinmanesh M, Kavosi Z. Risk factors for gastric cancer: a systematic review. Asian Pac J Cancer Prev 2018;19(3):591-603

10 Amarra S, Khor GL. Sodium consumption in Southeast Asia: an updated review of intake levels and dietary sources in six countries. In Bendich A, Deckelbaum RJ (eds). Preventive Nutrition: The Comprehensive Guide for Health Professionals; 2015:765-792

11 Tan CH, Chow ZY, Ching SM, et al. Salt content of instant noodles in Malaysia: a cross-sectional study. BMJ Open 2019;9(4):e024702

12 Lee YY, Wan Muda WAM. Dietary intakes and obesity of Malaysian adults. Nutr Res Pract 2019;13(2):159-168

13 Nagashekhara M, Murthy V, Mruthyunjaya AT. Li Ann L. An empirical study on traditional, complementary and alternative medicine usage among Malaysian cancer patients. Asian Pac J Cancer Prev 2015;16(15):6237-6241
14 Kim H, Hwang Y, Sung H, et al. Effectiveness of gastric cancer screening on gastric cancer incidence and mortality in a community-based prospective cohort. Cancer Res Treat 2018;50(2):582-589

15 Tanaka K, Kiyohara Y, Kubo M, et al. Secular trends in the incidence, mortality, and survival rate of gastric cancer in a general Japanese population: the Hisayama study. Cancer Causes Control 2005;16(5):573-578

16 Kim GH, Liang PS, Bang SJ, Hwang JH. Screening and surveillance for gastric cancer in the United States: is it needed? Gastrointest Endosc 2016;84(1):18-28

17 Hamashima C. Overdiagnosis of gastric cancer by endoscopic screening. World J Gastrointest Endosc 2017;9(2):55-60

18 Cui J, Liang H, Deng J, et al. [The impact of preoperative weight loss for gastric cancer patients after gastrectomy]. Zhonghua Wai Ke Za Zhi 2014;52(6):409-414

19 Sukri A, Hanafiah A, Kosai NR. Taher MM, Mohamed Rose I. Distribution of gastric adenocarcinoma subtypes in different ethnicities in Kuala Lumpur, Malaysia. Malays J Pathol 2017;39(3):235-242

20 Sisik A, Kaya M, Bas G, Basak F, Alimoglu O. CEA and CA 19-9 are still valuable markers for the prognosis of colorectal and gastric cancer patients. Asian Pac J Cancer Prev 2013;14(7):4289-4294

21 Feng F, Tian Y, Xu G, et al. Diagnostic and prognostic value of CEA, CA19-9, AFP and CA125 for early gastric cancer. BMC Cancer 2017;17(1):737

22 Căinap C, Nagy V, Gherman A, et al. Classic tumor markers in gastric cancer. Current standards and limitations. Clujul Med 2015;88(2):111-115 